\title{
Cruise shipping review: operations planning and research opportunities
}

Kai Wang and Shuaian Wang

Department of Logistics and Maritime Studies, The Hong Kong Polytechnic University, Kowloon, Hong Kong

\author{
Lu Zhen
}

School of Management, Shanghai University, Shanghai, China, and

\author{
Xiaobo Qu
}

School of Civil and Environmental Engineering, University of Technology Sydney, Sydney, Australia

\begin{abstract}
Purpose - This paper aims to conduct a review on cruise shipping and the cruise shipping industry. The current trends are analyzed for the industry, showing that this industry is still young and has great potential to boom. Meanwhile, the Asia market is the fastest growth region among the global, to which increasing cruise ships are repositioned by major cruise lines. However, for such a promising industry, the literature review on some state-of-the-art research works suggests that the research works that have been conducted for the cruise shipping are quite limited, and the majority of the works belongs to empirical and descriptive studies, which does not provide optimization-based quantitative analysis on some operation planning problems.

Design/methodology/approach - This paper conducts a review on cruise shipping and the cruise shipping industry.

Findings - In reality, there are some important operation planning problems faced by cruise lines or cruise ships, and four of them are addressed in this paper in response to the fast growing trend. The addressed operation planning problems are cruise fleet management, cruise ship deployment, cruise itinerary design and cruise service planning.

Originality/value - The importance and the attention for the research on the problems are also elaborated in the paper.
\end{abstract}

Keywords Itinerary planning, Cruise ship repositioning, Cruise shipping, Ship deployment

Paper type Literature review

\section{Introduction}

Cruise shipping uses a cruise ship or a cruise liner to provide cruise passengers with pleasure voyages. The voyages and the onboard activities bring rich experience and benefits for cruise passengers, as well as the shore excursion in ports of call along the way. For cruise shipping, different from liner shipping, transportation is not the

(C) Pacific Star Group Education Foundation

This research is supported by the National Natural Science Foundation of China (71422007) and Shanghai Social Science Research Program (2014BGL006).

Cruise shipping review

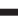
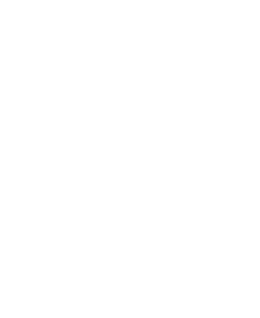
MABR 1,2

purpose, as cruise ships normally pick and return the cruise passengers at the same port and traverses a service route with some pre-determined ports of call.

Over the past two decades, the cruise industry had a dramatic development. In 2014, there were 296 cruise ships for all the cruise lines in the world (Cruise Industry News, 2015). With such a massive fleet, the cruise industry generated revenues of US\$37.1bn, and the number of cruise passengers reached a total of 22.04 million in 2014 (Statista, 2015) globally. Those cruise passengers were mainly from developed countries: among them, 12.16 million (55 per cent) were from North America, 6.39 million (29 per cent) were from Europe and 3.49 million (16 per cent) were from the rest of the world. However, as the cruising industry is an oligopolistic industry (Veronneau et al., 2015), the majority of the cruise market is shared by three cruise companies, which are Carnival, Royal Caribbean International and Norwegian Cruise Lines with market shares of 41.8, 21.8 and 8.2 per cent, respectively.

The cruise industry has been researched by many tourism researchers in past decades. Sun et al. (2011) conducted a concise review on the market research and revenue optimization for the cruise industry in which we can find that great efforts have been devoted into the cruise industry from the perspective of tourism management. However, the cruise shipping-related topics, which focus more on cruise ships, were somehow ignored in the past research works. In Sun et al. (2011), only two reviewed papers were related to itinerary design and optimization, which is an important topic in cruise shipping. In essential, cruise shipping is akin to the container liner shipping, and cruise shipping-related studies belong to maritime studies. They both follow a designed itinerary to finish a service for customers on sea and visit selected ports of call in the route. However, in contrast to the cruise shipping, there are tremendous research works on container liner shipping in maritime studies. See Meng et al. (2014) for an overview on the research works for liner shipping.

This paper conducts a review of cruise shipping and the cruise industry and proposes some research opportunities by analogizing from the research problems of liner shipping and by considering the characteristics of cruise shipping. At first, the industry trends are analyzed to provide a general picture for the industry trends. State-of-the-art related works on the cruise industry are reviewed in the next section, which are categorized into four research aspects, namely, regional analysis, risk management, environmental concerns and cruise shipping. Then, the paper addresses some research opportunities on cruise shipping for the cruise ships based on four planning problems, namely, cruise fleet management, cruise ship deployment, cruise itinerary design and cruise service planning. A specific problem of the cruise itinerary schedule design is also constructed as an example to demonstrate the research opportunities.

The remainder of the paper is organized as follows: the main industry trends are analyzed in Section 2. Detailed reviews on the past research works are given in Section 3. Section 4 addresses some operation planning problems in cruise shipping. A specific problem on cruise shipping is elaborated in Section 5. Final conclusions are drawn in Section 6.

\section{Industry trends}

The cruise industry is among the most exciting and fast-growing industry in tourism industries, and it is still young in the current stage. It has had an average passenger growth rate of 7.2 per cent per year since 1990. However, this industry is still young at the current stage and has strong potential to boom. According to Repositioning Cruises 
(2016), over the 29 years from 1980 to 2009, 176 million cruise passengers took cruising for their vacation. Of this number, nearly 70 per cent ( 40 per cent) was generated only by the past 10 years (past 5 years). Moreover, it is shown by investigation that over 50 million North Americans intend to take a cruise in the next three years.

The cruise industry aims to provide cruise passengers with a cheap and fun vacation by cruise ships. To reduce cruising cost and thereafter cut down cruising ticket price, huge investment has been made and is continuously made by cruise lines to improve their cruise ships' waste-disposal systems, fuel efficiency, back-up power systems, propulsion and safety in general (Repositioning Cruises, 2016). To keep pace with the preference of cruise passengers in terms of onboard activities, new cruise ships that enter service are equipped with more interesting and advanced entertainment equipment, for example, Quantum of the Seas, the cruise ship that entered the service for the Royal Caribbean International in 2014, has equipped with a first ever sky-diving simulator and a jewel-shaped capsule. These efforts made by the cruise line are already paying off. Compared with land vacation options, i.e. all kinds of resorts and hotels, the vacation by a cruise becomes more popular among travelers. The average occupancy ratio of the cruise ships is more than 90 per cent, but the average occupancy ratio of the hotels in North America is just around 50 per cent (Statista, 2015).

The Caribbean area and the Mediterranean area are two dominant areas in cruise shipping industry (Soriani et al., 2009), which are the two most popular cruising areas among the cruise passengers. However, in recent years, the cruise market in Asian area is booming. From 2012 to 2014, the Asian market has boomed for two times in terms of its share in the global market (Repositioning Cruises, 2016). According to Cruise Lines International Association, the Asian market is the fastest growth region (CLIA, 2014). As a result, the major cruise lines in the world decide to reposition more cruise ships for operations there and build their capacity in those fast-growing areas. For example, in 2016, the Royal Caribbean International plans to reposition a fleet of five large-capacity vessels to the region, i.e. Quantum, Ovation, Mariner, Legend and Voyager.

\section{State-of-the-art research works}

There are extensive research papers on cruise industry before 2010, and 145 cruise-related academic publications between 1983 and 2009 are collected by Papathanassis and Beckmann (2011). According to Sun et al. (2011), the majority of past research papers focused on marketing research and revenue optimization from the perspective of the tourism management, and only two reviewed paper in Sun et al. (2011) were related to the cruise shipping for the cruise ships. Therefore, in this section, we review the state-of-the-art research works since 2010 and investigate the research aspects on the cruise industry among the works. Here, based on our investigation, we summarize four aspects for the state-of-the-art research works, i.e. regional analysis, risk management, environmental concerns and cruise shipping.

\subsection{Regional analysis}

Among the state-of-the-art research works, significant part of the research is devoted to the regional cruise industry analysis in which the situation, development and trends in the cruise industry are investigated for different regions, such as the Mediterranean region and the Asian region. As one of dominant areas in the cruise shipping industry, the Mediterranean area still attracts some researchers' attention. Based on the 
MABR 1,2

background of the Mediterranean region, Gui and Russo (2011) constructed an analytic framework connecting the global structure of cruise value chains to the regional land-based cruise services. They pointed that the cruise tourism heavily relies on local attractions, and substantial extra-revenues are gained by the shore excursions, which emphasizes on the cooperation among cruise liners, ports and cities.

Meanwhile, the fast-growing cruising regions are increasingly popular in the sense of the research activities, such as the Asian region and the South American region. For the Asian region, Sun et al. (2014) summarized the history and growth of the cruise industry in China, reported the characteristics of Chinese cruise passengers and analyzed the major cruise ports in China, based on which they discussed some challenges and managerial implications for developing the cruise tourism in China. Catering to the great potential for the Asian region in the cruise tourism, Chen (2016) explored how Taiwan could build a niche in Asian cruise tourism industry, which makes Taiwan a cruise service center in the Asian region. For the South American region, Diedrich (2010) investigated the implications of developing the cruise tourism in Belize, which is an ecotourism destination in South America. Based on the data analysis for the cruise tourism in Brazil, Robles et al. (2015) suggested that the Brazilian market has changed its status from an emergent local market to an established market with defined niches, but there is still good potential to further grow. Australia is another rapid growth region in the cruise industry, and the growth in the region was summarized by Dowling (2011).

The majority of the above-mentioned research works for the regional analysis belong to conceptual and discussion papers, which are normally empirical studies or field studies to investigate the regional development and trends. Data collection and analysis are the major methodologies for the studies to draw insights on the regional cruise industry. For all the different regions, all researchers hold the opinion that there is great potential for the cruise market to grow, which verifies the importance of the cruise industry in the sense of research.

\subsection{Risk management}

Risk management is critical in the cruise industry for the safety of cruise passengers, crew members and cruise ships. Cruise ships can carry thousands of cruise passengers and crew members. If some accidents happen, such a concentration of people could lead to some unpredictable disasters. The sinking of the RMS Titanic is a typical disaster for passenger ships, which leads to deaths of more than 1,500 people. For a recent case, the Italian cruise ship Costa Concordia capsized and sank in Isola del Giglio, Tuscany, on January 13, 2012. This case resulted in the loss of 32 lives. To avoid such disasters and other safety issues for the cruise ships and strengthen the effectiveness of risk management, in the recent research works, many researchers studied the safety and risk assessment approaches for the cruise ships.

Mileski et al. (2014) proposed a two-stage measurement design to analyze the reasons of recent ship disasters and mishaps. According to the findings of their research, the most common cause was the lack of proper maintenance on the cruise ships, leading to 60.52 per cent of the mishaps, followed by human error by crew members at 26.2 per cent. Vidmar and Perkovic (2015) proposed a formal safety assessment to determine and evaluate the risk of potential hazards for cruise ships in a port, in which different probabilistic, deterministic and qualitative approaches (e.g. event tree) were presented to govern the cruise transportation risk. Vairo et al. (2016) developed a 
consequence-based framework incorporating the effects, the hazardous distance and the reaction time scale related to fuel spill and fire scenarios with smoke spreading for the cruise ships. The results of their study even showed that the proposed approach can be a good tool to design cruise shipping routes. Vassalos (2016) applied different mathematical formulations and Monte Carlo simulation to estimate the damage survivability of cruise ships and emphasized on the continuous safety improvement for the cruise ships. Lu and Tseng (2012) did not study the safety of cruise ships but focused on the safety of passenger ferry ships. They defined crucial safety assessment criteria using empirical methods and found that that crew members' abilities are the critical factors in assessing passenger ferry safety, which is consistent with the findings of Mileski et al. (2014).

Risk management is critical for different industries, especially for the industries that can lead to a concentration of people. The risk management for the cruise industry concentrates on the risk or safety assessment for the cruise ships based on the above-mentioned research works.

\subsection{Environmental concerns}

Cruise tourism is not an ecotourism. The cruise industry incurs some environmental concerns. Caric (2016) mentioned several cruise ship pollution cases, such as ship emissions, oil leakage and waste water. The major environmental concern is ship emissions. As a part of maritime transportation, both cruise shipping and liner shipping share the same key concern. According to a report by International Maritime Organization (IMO, 2015), international shipping contributed to 2.2 per cent of the world's total $\mathrm{CO}_{2}$ emissions in 2012. The shipping vessels released roughly 15 and 13 per cent of anthropogenic $\mathrm{NO}_{\mathrm{x}}$ and $\mathrm{SO}_{\mathrm{x}}$ into the atmosphere, respectively, because of the burning of oil by power engines (IMO, 2015). To protect the environment, IMO has released a number of regulations over past years, and establishing four distinct "Emission Control Areas" (ECAs) is one of them. All the ships passing through the ECAs must restrict the ship emissions of $\mathrm{NO}_{\mathrm{x}}$ and $\mathrm{SO}_{\mathrm{x}}$.

To comply with the concern, there have been plenty of research works on ship emissions for the cruise ships. Howitt et al. (2010) calculated the greenhouse emissions (i.e. $\mathrm{CO}_{2}$ emissions) caused by cruise shipping in New Zealand. Walsh and Bows (2012) investigated the effects of ship sizes and characteristics on ship emissions. Poplawski et al. (2011) investigated the impacts of cruise ship emissions for Victoria. Similarly, Maragkogianni and Papaefthimiou (2015) evaluated the air emissions by cruise ships for the major cruise ports in Greece. Dragovic' et al. (2016) proposed an estimation and analysis of ship exhaust emissions and their externalities in the popular cruise destinations of Dubrovnik and Kotor.

For all those research works on ship emissions, the researchers focused more on cruise ship emissions for specific cruise ports, which suggests that the cruise ports are suffering from the air pollution by cruise ships. Fortunately, there is a novel technology to significantly reduce the cruise ship emissions in cruise ports, i.e. cold-ironing. Cold-ironing is a developed technology that enables cruise ships to use shore power when berthed at cruise ports and turn off their auxiliary engines for electricity generation. Thus, the harmful emissions released by auxiliary engines can be reduced significantly (Sciberras et al., 2015). Ballini and Bozzo (2015) investigated the feasibility to apply cold-ironing technology in cruise ships and presented a study case for the cruise 
MABR

1,2 port of Copenhagen. According to their research, 60 per cent cruise ships are new and large vessels that can be compatible with the cold-ironing technology, but the cold-ironing facilities are not available in the majority of cruise ports. Based on their research, it is recommended that future research efforts can be devoted to the cold-ironing penetration, such as studying the economic viability of establishing the cold-ironing facilities and studying the pricing for power charging by cold-ironing technology in cruise ports.

\subsection{Cruise shipping}

For the cruise shipping topic, we try to review the papers that treat cruise shipping as a part of maritime transportation, just like liner shipping. Rodrigue and Notteboom (2013) argued that the cruise industry sells itineraries, not destinations, and they also concluded that ship deployment and itinerary design by cruise operators are primordial. Their research demonstrates that cruise shipping planning is close to liner shipping planning in which the ship deployment and itinerary design are also critical and various itineraries are the selling points. Wang et al. (2014) used the fuzzy-AHP method to select a cruise port of call location and identified the main motivations for cruise lines on the port selection. Maddah et al. (2010) developed a discrete-time dynamic capacity control model for a cruise ship to increase revenue by suggesting the cruise ship manager on whether to accept a booking. In liner shipping, a liner ship also faces the problem on accepting container transportation orders with limited capacity. Lau et al. (2014) presented a critical problem for the cruise shipping, i.e. the lack of berths in major cruise terminals. According to Lau et al. (2014), the Kai Tak Cruise Terminal in Hong Kong with two berths is struggling to fulfill the demand by cruise shipping.

Here, compared with the other three research aspects (regional analysis, risk management and environmental concerns), cruise shipping is in the lowest attention, as few research works are strongly related to cruise shipping. However, based on papers reviewed for cruise shipping and our previous discussion, cruise shipping and liner shipping are analogical in the sense of research. Thus, in the next section, we will propose some research opportunities for cruise shipping based on the characteristics of the cruises and the research problems in the liner shipping.

\section{Research opportunities in the operations planning of cruise shipping}

For the operations planning of the cruise shipping, a few strategic or tactical decisions have long-lasting effect on the profitability of their cruise ships (Veronneau and Roy, 2009). In cruise shipping, there are some important operation planning problems in the strategic or tactical levels that have not been touched by previous researchers. In this section, we summarize four operations planning, i.e. cruise fleet management, cruise ship deployment, cruise itinerary design and cruise service planning, and propose some research opportunities based on the characteristics of the cruises and the research problems in liner shipping. The future quantitative research can be conducted in such decision problems to further increase the profit earned by the cruise lines, reduce the cost for the cruise ships and improve the service experience of the cruise passengers from the perspective of cruise shipping.

\subsection{Cruise fleet management}

According to Statista (2015), the cruise ship fleet worldwide keeps steady increase along the years. Figure 1 shows the number of cruise ships of the cruise ship fleet worldwide 
from 2008 to 2019. There was a clear downward trend in 2009, which is explainable considering the financial crisis in 2009. As tourism, the cruise industry suffers significantly from the crisis. Before 2009, the Carnival Line had signed agreements with three shipyards providing for the construction of 17 additional cruise ships scheduled to enter service between March 2009 and June 2012, which were all postponed or canceled because of the crisis. However, in the long-term trend, the cruise ship fleet worldwide still keeps a steady expansion. Based on current agreements between the cruise lines and shipyards, 25 additional cruise ships will enter service in 2019 compared with the fleet in 2014.

The biggest three cruise lines, i.e. Carnival, Royal Caribbean International and Norwegian Cruise Lines, maintain the fleets of 102, 43 and 13 cruise ships, respectively. These cruise lines keep booking new ships to replace the scrapped, damaged or lost ships, fulfill the rising trend of the cruising market and provide extra capacity to block potential new entrants from entering into the market. Considering the economies of scale for the cruise ships, currently, the cruise lines intend to book large cruise ships. A large cruise ship has over 5,000 lower berths and may cost over US $\$ 1$ bn to construct. Thus, the cruise line should carefully analyze the cruising market and decide the expansion of their cruise fleets, as the cost of ordering a large cruise ship is high.

The maintenance of a fleet is critical to keep the safety of running cruise ships and to ensure the long-term operation of the cruise ships. According to Mileski et al. (2014), 60.52 per cent of the mishaps are attributed to poor routine maintenance. However, a ship out of service for a week for routine maintenance means the loss of tens of millions of dollars and thousands of dissatisfied customers. The cruise lines want to operate their ships all year round without any break, as cruise ships do not make money unless they are operating. Therefore, there is a trade-off on the fleet maintenance and the opportunity cost.

In the ship fleet management of liner shipping, ship fleet size is concerned with the number of ships that a liner shipping company keeps in the fleet. Meng and Wang (2011) studied a multi-period fleet planning problem for container ships, which is similar to the case of cruise ships. They assumed that container ship demand varied over different periods, and that the liner shipping company can sell, purchase, charter in and charter out ships at each period. This problem can be analogized to cruise shipping. The cruise lines could also sell, purchase, charter in and charter out the cruise ships for different periods in response to the demand variations. In the current situation, the growing trend in the following several years for cruise shipping is acknowledged. However, the cruise

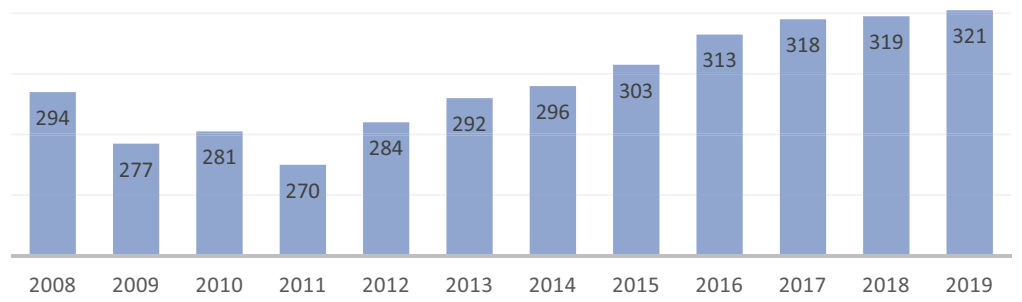

Figure 1.

Cruise ship fleet worldwide from 2008

Source: Statista (2015) 
MABR 1,2

ships are normally mega-ships, which generally remain in service for a period of 20-30 years once they enter service. If many cruise ships enter service from now on and the cruising market in two-three decades does not boom significantly, the cruise lines may suffer from the fleet planning decisions that have been made. Thus, it is practical to consider the fleet planning problem for cruise shipping.

\subsection{Cruise ship deployment}

Some cruise ships are routinely relocated from the Caribbean to Alaska in summer or from the Mediterranean to the Caribbean in winter to appeal to more cruise passengers in different seasons. The seasonal variation is a dominant effect on the ship deployment and repositioning. Meanwhile, as the Caribbean market and the Mediterranean market are saturated at the present stage, the cruise lines are now opting to relocate some of their cruise ships to Asia to gain profit from the fast-growing Asian market.

Here come the problems: how to relocate cruise ships from one region to another region with considering the seasonal variations, and how many cruise ships are deployed for a specific region, e.g. the Asian area. Cruise ships are different from container liner ships. In the liner ship deployment, the capacity of container ships is the major concern. However, in the cruise ship deployment, apart from the capacity, the consideration for the onboard activities is essential. If a cruise ship has been deployed in a region for a long time, it needs to be relocated, as its onboard activities are no longer appealing to the potential local cruise passengers, and other cruise ships need to be deployed in the region to provide the feeling of freshness for the local market.

Among the research works for the ship deployment in liner shipping, the majority of the works combined the ship deployment with other decisions, such as speed optimization (Gelareh and Meng, 2010) and container transshipment operations (Wang and Meng, 2012). Here, the speed optimization is strongly related to the bunker consumption of ships, and different types of ships have different relations between the sail speed and the bunker consumption (Du et al., 2011; Zhen et al., 2016). In cruise shipping, an integrated problem on the cruise ship deployment and sailing speed optimization can also be studied, as there is a trade-off among the capacity, the bunker consumption and the onboard activities of the cruise ships in different types.

\subsection{Cruise itinerary design}

A cruise itinerary is a cruise route operated by a cruise company. A cruise ship picks up cruise passengers at an embarkation port, calls at a set of ports of call for cruise passengers to visit the port cities and returns to a disembarkation port where cruise passengers get off the cruise ship. Generally, there are two kinds of cruise itineraries, i.e. one-way itineraries and loop itineraries. The embarkation port and the disembarkation are two different ports in one-way itineraries and are the same port in the loop itineraries. One-way itineraries are often designed to reposition the cruise ship from one area to another area, such as "13 Days Transatlantic from Barcelona to New York" cruise and "11 Days Southern Caribbean from New York to Miami" cruise by Carnival Vista (a cruise ship belonging to the Carnival Cruise Line). The purpose of these two cruise itineraries is to reposition the cruise ship from the Mediterranean area to the Caribbean area. Once the cruise ship is repositioned, it usually operates loop cruise itineraries in the Caribbean area with Miami as the embarkation port and disembarkation port. One example for a loop cruise itinerary is given in Figure 2. 


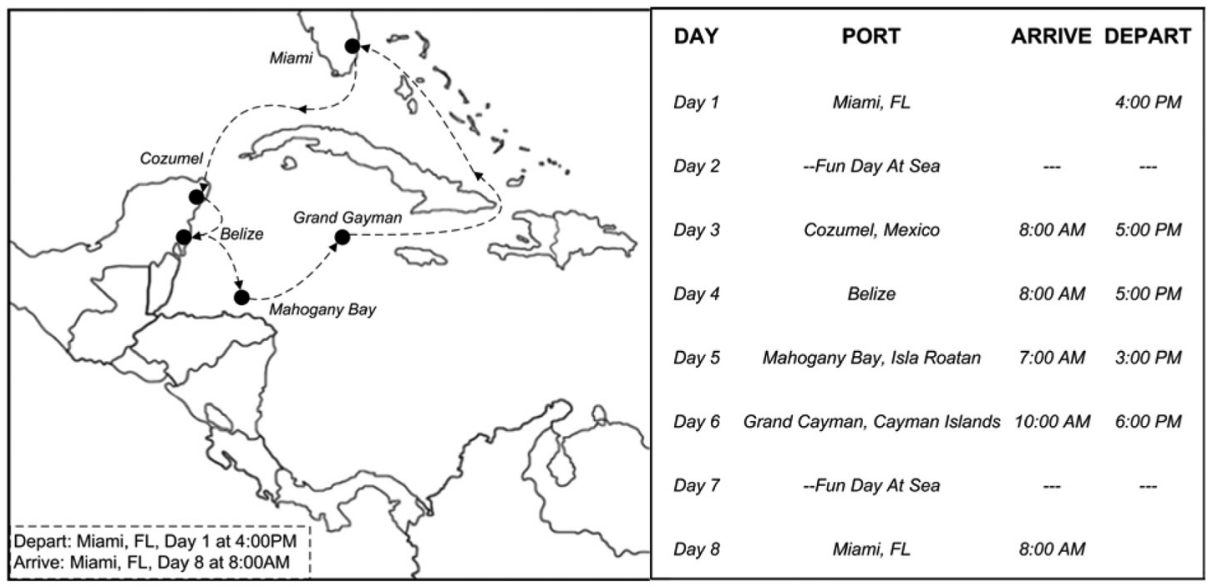

Source: Adapted from Carnival Cruise Line (2016)
Cruise shipping review

141

Figure 2.

The itinerary of seven-day Western

Caribbean of Carnival

4.3.1 Home port selection. When a cruise ship is relocated to a new region for the sake of seasonal variations or market repositioning, the priority for the cruise ship is to select a home port, i.e. the port where the cruise passengers embark and disembark. Miami is the home port when the Carnival Vista is repositioned to the Caribbean area. As a home port, the port acts as the base for a cruise ship, which takes passengers around a cruise circuit and then comes back to the homeport to berth. For cruise passengers, they either "fly in" or "drive in" to the home port to take their cruise. The choice of home ports by cruise companies highly depends on the passenger market, the air-lift capacity of the port city and the infrastructure and services of the port (e.g. fuel charges) (Brida et al., 2013). In Mediterranean area, the second most popular cruise area, the top three home ports are Venice, Barcelona and Civitavecchia, sharing 51.2 per cent of the total home in/out cruise passengers (Esteve-Perez and Garcia-Sanchez, 2014).

4.3.2 Ports of call selection. Although the cruise passengers spend most of their time on board in a cruise, the shore excursions in ports of call are primary selling points for the cruise to appeal to the cruise passengers. The attractions in the ports of call are the priority in the selection, as more interesting attractions could draw more potential cruise passengers' attention. Closeness to the itinerary should be considered, for example, if the itinerary is loop in the Caribbean area with the home port Miami, New York cannot be set as a port of call, as it is too far away from Miami. Meanwhile, the infrastructure in the ports of call determines whether the cruise ship can dwell at the ports. Most cruise ships are megaships, and the largest ship (Allure of the Seas) has 225,282 gross tonnages with a length of $386 \mathrm{~m}$ and a beam of $65 \mathrm{~m}$. This poses great challenges for small ports to accommodate such large cruise ships.

4.3.3 Itinerary schedule design. Given a home port (or two home ports in one-way itinerary) and a set of ports of call, the next step is to design itinerary schedule (see right-side of Figure 1 for an itinerary schedule), which aims to determine a sequence of the ports of call to visit and the arrival and departure times at the port of call. The 
MABR

1,2

optimal sequence of the ports of call to visit is mainly determined by geographical distances. In general, a shorter overall itinerary distance means less fuel consumed and, thereby, significant bunker cost savings. However, determining the sequence of ports of call simply based on the overall itinerary distance may not be optimal. For example, quite often, the ports of call are close to each other, as is the case of the Caribbean and Mediterranean areas, and different sequences may not have much effect on the overall distance.

For the itinerary schedule design, we will elaborate a specific quantitative optimization problem, which is shown in Section 5 and can be deemed as an example to demonstrate the research opportunities.

\subsection{Cruise service planning}

A cruise service operated by a cruise ship is a cruise itinerary. In such a cruise itinerary, the cruise ship picks up cruise passengers at an embarkation port, visits the ports of call involved in the cruise route and returns to the embarkation port where cruise passengers get off the cruise ship. To finish a service, certain rotation time is needed, which is the number of days to traverse the cruise route. According to Cruise Ship Schedule (2016), the rotation time of the services for The Carnival Vista (a cruise ship) ranges from 4 to 13 days. Operating a service brings decent profit for a cruise ship, as the cruise passengers spend several days in the cruise ship in which cruise passengers spend considerable money on tickets, special food and entertainment. Generally, the longer the cruise passengers stay in the cruise ship, the more profit the cruise ship will earn.

4.4.1 Cruise itinerary selection. When a cruise ship is repositioned to a new area for a period of time (e.g. Summer), given some designed cruise services (i.e. cruise itineraries), the decision left for the cruise ship is to select the cruise services for operation and to schedule them one by one in the period. To maximize the total profit brought by operating cruise services is a straightforward target in the selection. This target could address another problem: how to estimate the profit that can be earned by operating a cruise service. The simplest way to estimate the profit is to forecast the number of cruise passengers for the cruise service and assess the average profit earned per cruise passenger. In such way, a phenomenon in the real situation should be considered: when a cruise service is operated (repeated) more times, fewer potential cruise passengers would order such a cruise service per repetition.

Fulfilling a cruise service not only requires efforts from the cruise ships but also needs the cooperation from the cruise terminals of the ports of call as the cruise ships request berths when visiting the ports. However, the berths in major cruise terminals are quite limited. For example, Wusong Kou cruise terminal (Shanghai) and Kai Tak cruise terminal (Hong Kong) just have the berth capacity to serve two cruise ships simultaneously (Lau et al., 2014). Thus, selecting a cruise service to operate or not is not the single decision taken by the cruise ships, and it also needs the negotiation between the cruise ships and the cruise terminals.

4.4.2 Cruise itinerary changes. Although a schedule of cruise itineraries can be planned in advance, in real situation, there are several factors and circumstances that can lead to a change in cruise schedule (and often of itinerary):

- The weather condition in ports of call could have significant impacts on the arrival times and departure times.

- In some ports, cruise times can be changed because of air pressure or tidal times. 
- Cruise schedule changes also because of mechanical problems or an incident/ accident.

- Itineraries may be changed by the cruise lines, based on some safety concerns.

Cruise shipping review

Thus, a pre-determined schedule can be changed significantly in the real-world implementation.

\section{A specific research problem on the itinerary schedule design}

In this section, we construct a specific quantitative optimization problem, which is an itinerary schedule design (ISD) problem and a potential research problem. The ISD problem focuses on schedule design for a cruise itinerary with a given home port and a set of given ports of call. The optimal sequence of the ports of call to visit and the arrival and departure time at the ports of call are to be determined. For the problem, by determining the sequence of the ports of call to visit and the arrival and departure time at the ports of call, there is a trade-off between the voyage time on sea and the dwelling time at ports. The sequence determines the travel distance of the itinerary and thereafter has effects on the voyage time. The arrival and departure time at the ports of call determine the dwelling time at ports. Normally, the rotation time for a cruise is pre-determined (for the example in Figure 2, it is seven days), which is divided into the voyage time and dwelling time. Thus, the longer the voyage time is, the shorter the dwelling time is. The voyage time is strongly related to the bunker consumption of the ship (Wang et al., 2013). The dwelling time gives the cruise passengers opportunities to tour in port cities by which the benefits or experience (i.e. utility) can be brought for cruise passengers. Then, the aim of the problem is to minimize the bunker consumption and maximize the utility for the cruise passengers from the ports by designing the optimal sequence of the ports of call to visit and the arrival and departure time at the ports of call.

\subsection{Utility distribution at ports of call}

For the time spent at a port city (i.e. the dwelling time), we notice that cruise ships normally visit a port of call in the morning and leave in the evening so that cruise passengers can tour around the port city. Apparently, if the cruise ship arrives at the port of call at, for example, 1:00 a.m., then there is no place for the cruise passengers to visit or enjoy. To measure the benefits or experience that can be brought for cruise passengers, we need to know the utility of a port among different hours of a day. Figure 3 illustrates an example of the utility distribution of a port. In the daytime hours, the utility is positive. In the night hours, when the port is closed, the utility is zero. The utility for each hour can be estimated by expert judgment. Some research works can also be conducted on the utility estimation. To synthesize the total amount of utility that the cruise passengers will experience with the cost in the bunker consumption, we denote $p^{u}$ as the monetary value brought by one unit of utility for the cruise line.

\subsection{Bunker consumption among voyages}

Different arrival and departure times at ports and the port sequence affect the sailing speed among voyages, which has impacts on the bunker consumption of the cruise ship. According to Du et al. (2011), based on the sailing speed, the bunker consumption ratio can be estimated as follows: 


\section{MABR}

1,2

\section{4}

\section{Figure 3.}

The utility distribution for one day

\section{Utility Distribution}

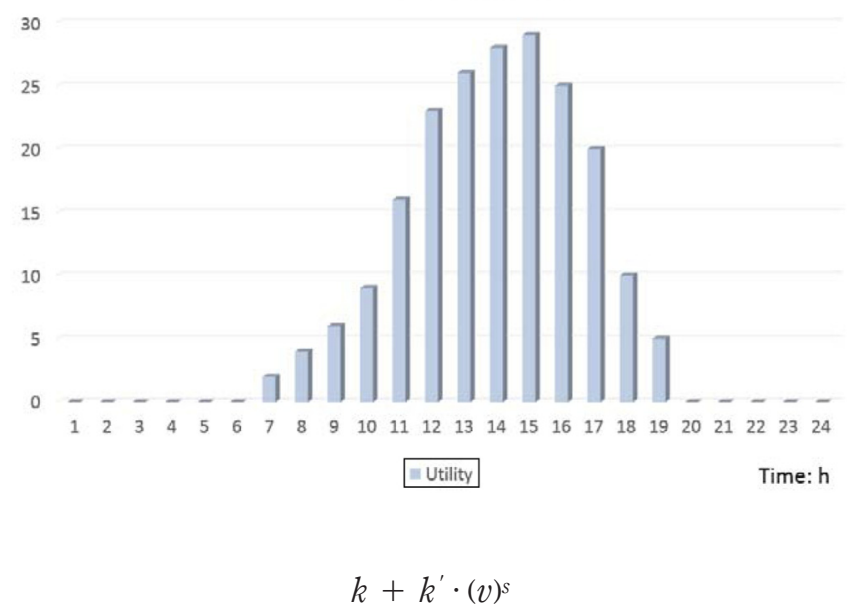

where $k$ and $k^{\prime}$ are regression coefficients, $v$ is the sailing speed of the cruise ship and $s \in$ $\{3.5,4,4.5\}$. Let $d$ be the distance of the leg (the voyage between two adjacent ports of call) and $t$ be the sailing time on the voyage, then the speed is $v=d / t$. Therefore, the bunker consumption on the leg, denoted by function $F(d, t)$, is:

$$
F(d, t)=\left[k+k^{\prime} \cdot(v)^{s}\right] \cdot t=k t+k^{\prime} d^{s} t^{1-s}
$$

To convert the bunker consumption into the bunker cost, the unit price of bunker, denoted by $c^{F}$, is needed as an input. Here, for the bunker consumption, there are some optimization methods to further reduce the bunker consumption, such as slow streaming (see Wang et al. (2013) for the details of the methods).

\subsection{Problem framework}

In the ISD problem, the following inputs are required:

- the time that the cruise ship leaves from the home port, the time that cruise ship returns to the home port and the total rotation time of the cruise;

- the utility distribution at each port of call for the cruise passengers to experience, where the utility represents the benefits or experience brought by the cruise service for cruise passengers; and

- the relationship between bunker consumption and speed on each voyage leg.

Then, based on these inputs, we make two critical decisions:

(1) the sequence of the ports of call for the cruise ship to visit one by one; and

(2) the arrival and departure times at each port of call.

The objective of the ISD problem is to maximize the total monetary value brought by the utilities that cruise passengers experience at port cities minus the bunker cost of the cruise ship to traverse the cruise itinerary. 
The ISD problem is a practical problem faced by cruise lines. This problem can be studied in a quantitative manner by mathematical modeling, and optimization-based methods can be developed for the problem. Our future study will focus on this problem.

\section{Cruise shipping review}

\section{Conclusions}

This paper conducts a review on cruise shipping and the cruise industry. The relevant reports show that the cruise shipping industry is a booming industry, which has kept steady increase over the past several decades and still has plenty of room to grow. Among cruise market areas in the world, the Caribbean area and the Mediterranean area are the two dominant cruising destinations. The Asian area has the fastest growth rate in cruise market. Thus, an increasing number of cruise ships are repositioned to the area by the major cruise lines. In fact, these trends suggest that there are great research values and research opportunities on cruise shipping in terms of operations planning. The literature review on the state-of-the-art research works since 2010 for the cruise industry is conducted from four research aspects, i.e. regional analysis, risk management, environment concerns and cruise shipping. Based on the research works and our discussion on cruise shipping, cruise shipping is akin to container liner shipping. By analogizing liner shipping and by considering the characteristics of cruise shipping, research opportunities are proposed and a specific research problem is constructed, which forms an example to demonstrate the research opportunities.

The aim of cruise shipping is to provide the cruise passengers with a cheap and fun vacation. Significant efforts have been devoted into the improvements of cruise ships, for example, improving the fuel efficiency. The research on the operation planning problems should keep pace with the improvements to further increase the profit earned by the cruise lines, reduce the cost for the cruise ships and improve the service experience of the cruise passengers. The general four operation planning problems (i.e. the research opportunities) identified in this paper are cruise fleet management, cruise ship deployment, cruise itinerary design and cruise service planning. It is recommended that increasing research efforts are allocated to the proposed problems and other relevant operation problems in cruise shipping.

\section{References}

Ballini, F. and Bozzo, R. (2015), "Air pollution from ships in ports: the socio-economic benefit of cold-ironing technology", Research in Transportation Business \& Management, Vol. 17 No. 1, pp. 92-98.

Brida, J.G., Pulina, M., Riaño, E. and Aguirre, S.Z. (2013), "Cruise passengers in a homeport: a market analysis", Tourism Geographies, Vol. 15 No. 1, pp. 68-87.

Caric, H. (2016), "Challenges and prospects of valuation e cruise ship pollution case", Journal of Cleaner Production, Vol. 111 No. 1, pp. 487-489.

Carnival Cruise Line (2016), "7 day Western Caribbean from Miami”, FL, available at: www. carnival.com/itinerary/7-day-western-caribbean-cruise/miami/glory/7-days/wek (accessed 4 April 2016).

Chen, C.A. (2016), "How can Taiwan create a niche in Asia's cruise tourism industry?", Tourism Management, Vol. 55 No. 1, pp. 173-183.

CLIA (Cruise Line International Association) (2014), “Asia cruise trends: 2014 edition”, available at: www.cruising.org/docs/default-source/research/asiacruisetrends_2014_finalreport-4. pdf (accessed 11 June 2016). 
MABR

1,2

Cruise Industry News (2015), “Cruise industry statistics - Cruise ship statistics”, available at: www.cruiseindustrynews.com/cruise-industry-stats.html (accessed 9 April 2016).

Cruise Ship Schedule (2016), "Carnival Vista itinerary 2016 cruises", available at: www. cruiseshipschedule.com/carnival-cruise-lines/carnival-vista-schedule/ (accessed 7 April 2016).

Diedrich, A. (2010), "Cruise ship tourism in Belize: the implications of developing cruise ship tourism in an ecotourism destination”, Ocean \& Coastal Management, Vol. 53 No. 1, pp. 234-244.

Dowling, R. (2011), "Research note: the growth of cruising in Australia”, Journal of Hospitality and Tourism Management, Vol. 18 No. 1, pp. 117-120.

Dragović, B., Tzannatos, E., Tselentis, V., Meštrović, R. and Škurić, M. (2016), "Ship emissions and their externalities in cruise ports", Transportation Research Part D: Transport and Environment, in press, doi: 10.1016/j.trd.2015.,11.007.

Du, Y., Chen, Q., Quan, X., Long, L., Fung, R.Y.K. (2011), "Berth allocation considering fuel consumption and vessel emissions", Transportation Research Part E: Logistics and Transportation Review, Vol. 47, pp. 1021-1037.

Esteve-Perez, J. and Garcia-Sanchez, A. (2014), "Cruise market: Stakeholders and the role of ports and tourist hinterland", Maritime Economics and Logistics, Vol. 17 No. 3, pp. 1-18.

Gelareh, S. and Meng, Q. (2010), “A novel modeling approach for the fleet deployment problem within a short-term planning horizon”, Transportation Research Part E: Logistics and Transportation Review, Vol. 46 No. 1, pp. 76-89.

Gui, L. and Russo, A.P. (2011), "Cruise ports: a strategic nexus between regions and global lines evidence from the Mediterranean", Maritime Policy \& Management, Vol. 38 No. 2, pp. 129-150.

Howitt, O.J.A., Revol, V.G.N., Smith, I.J. and Rodger, C.J. (2010), "Carbon emissions from international cruise ship passengers' travel to and from New Zealand”, Energy Policy, Vol. 38 No. 5, pp. 2552-2560.

IMO (2015), "Third IMO GHG Study 2014: Key findings from the Third IMO GHG Study", available at: www.imo.org/en/ourwork/environment/pollutionprevention/airpollution/ pages/greenhouse-gas-studies-2014.asp (accessed 11 June 2016).

Lau, Y., Tam, K., Ng, A.K.Y. and Pallis, A.A. (2014), “Cruise terminals site selection process: an institutional analysis of the Kai Tak Cruise Terminal in Hong Kong”, Research in Transportation Business \& Management, Vol. 13 No. 1, pp. 16-23.

Lu, C.S. and Tseng, P. (2012), "Identifying crucial safety assessment criteria for passenger ferry services", Safety Science, Vol. 50 No. 7, pp. 1462-1471.

Maddah, B., Moussawi-Haidar, L., El-Taha, M. and Rida, H. (2010), "Dynamic cruise ship revenue management”, European Journal of Operational Research, Vol. 207 No. 1, pp. 445-455.

Maragkogianni, A. and Papaefthimiou, S. (2015), "Evaluating the social cost of cruise ships air emissions in major ports of Greece", Transportation Research Part D: Transport and Environment, Vol. 36 No. 1, pp. 10-17.

Meng, Q. and Wang, S. (2011), "A scenario-based dynamic programming model for multi-period liner ship fleet planning", Transportation Research Part E: Logistics and Transportation Review, Vol. 47 No. 4, pp. 401-413.

Meng, Q., Wang, S., Andersson, H. and Thun, K. (2014), "Containership routing and scheduling in liner shipping: overview and future research directions", Transportation Science, Vol. 48 No. 2, pp. 265-280. 
Mileski, J.P., Wang, G. and Beacham, L.L. (2014), "Understanding the causes of recent cruise ship mishaps and disasters”, Research in Transportation Business \& Management, Vol. 13 No. 1, pp. 65-70.

Papathanassis, A. and Beckmann, I. (2011), “Assessing the "poverty of cruise theory" hypothesis", Annals of Tourism Research, Vol. 38 No. 1, pp. 153-174.

Poplawski, K., Setton, E., McEwen, B., Hrebenyk, D., Graham, M. and Keller, P. (2011), "Impact of cruise ship emissions in Victoria, BC, Canada”, Atmospheric Environment, Vol. 45 No. 4, pp. 824-833.

Repositioning Cruises (2016), “Cruise Industry overview, trends and cruise market”, available at: www.repositioncruises.com/cruise-industry/\#statistics (accessed 11 April 2016).

Robles, L.T., Galvão, C.B. and Pereira, S.R. (2015), "Cruise shipping in Brazil: an emergent or established market?”, Tourism Management Perspectives, Vol. 16 No. 1, pp. 298-305.

Rodrigue, J. and Notteboom, T. (2013), “The geography of cruises: Itineraries, not destinations”, Applied Geography, Vol. 38, pp. 31-42.

Sciberras, E.A., Zahawi, B. and Atkinson, D.J. (2015), "Electrical characteristics of cold ironing energy supply for berthed ships", Transportation Research Part D: Transport and Environment, Vol. 39 No. 5, pp. 31-43.

Soriani, S., Bertazzon, S., Cesare, F.D. and Rech, G. (2009), "Cruising in the Mediterranean: structural aspects and evolutionary trends”, Maritime Policy \& Management, Vol. 36 No. 3, pp. 235-251.

Statista (2015), "Cruise industry - Statista Dossier: facts and statistics on the cruise industry", available at: www.statista.com/study/11547/cruise-line-industry-statista-dossier/ (accessed 7 April 2016).

Sun, X.D., Jiao, Y. and Tian, P. (2011), "Marketing research and revenue optimization for the cruise industry: a concise review”, International Journal of Hospitality Management, Vol. 30 No. 3, pp. 746-755.

Sun, X.D., Feng, X.G. and Gauri, D.K. (2014), "The cruise industry in China: efforts, progress and challenges", International Journal of Hospitality Management, Vol. 42 No. 1, pp. 71-84.

Vairo, T., Quagliati, M., Giudice, T.D., Barbucci, A. and Fabiano, B. (2016), "From land- to water-use-planning: a consequence based case-study related to cruise ship risk", Safety Science, in press, doi: 10.1016/j.ssci.2016.,03.024.

Vassalos, D. (2016), "Damage survivability of cruise ships - Evidence and conjecture", Ocean Engineering, Vol. 121 No. 1, pp. 89-97.

Veronneau, S. and Roy, J. (2009), "Global service supply chains: an empirical study of current practices and challenges of a cruise line corporation”, Tourism Management, Vol. 30 No. 1, pp. 128-139.

Veronneau, S., Roy, J. and Beaulieu, M. (2015), “Cruise ship suppliers: a field study of the supplier relationship characteristics in a service supply chain”, Tourism Management Perspectives, Vol. 16 No. 1, pp. 76-84.

Vidmar, P. and Perkovic, M. (2015), "Methodological approach for safety assessment of cruise ship in port”, Safety Science, Vol. 80 No. 1, pp. 189-200.

Walsh, C. and Bows, A. (2013), "Size matters: exploring the importance of vessel characteristics to inform estimates of shipping emissions”, Applied Energy, Vol. 98 No. 1, pp. 128-137.

Wang, S. and Meng, Q. (2012), "Liner ship fleet deployment with container transshipment operations", Transportation Research Part E: Logistics and Transportation Review, Vol. 48 No. 2, pp. 470-484. 
MABR

1,2

148

Wang, S., Meng, Q. and Liu, Z. (2013), "Bunker consumption optimization methods in shipping: a critical review and extensions", Transportation Research Part E: Logistics and Transportation Review, Vol. 53 No. 1, pp. 49-62.

Wang, Y., Jung, K.A., Yeo, G.T. and Chou, C.C. (2014), “Selecting a cruise port of call location using the fuzzy-AHP method: a case study in East Asia", Tourism Management, Vol. 42, pp. 262-270.

Zhen, L., Shen, T., Wang, S. and Yu, S. (2016), "Models on ship scheduling in transshipment hubs with considering bunker cost", International Journal of Production Economics, Vol. 173 No. 11, pp. 111-121.

\section{Further reading}

Fransoo, J.C. and Lee, C.Y. (2013), “The critical role of ocean container transport in global supply chain performance”, Production and Operations Management, Vol. 22 No. 2, pp. 253-268.

\section{Corresponding author}

Lu Zhen can be contacted at: 1zhen@shu.edu.cn

For instructions on how to order reprints of this article, please visit our website: www.emeraldgrouppublishing.com/licensing/reprints.htm Or contact us for further details: permissions@emeraldinsight.com 